\title{
Cancer chemoresistance and therapeutic strategies targeting tumor microenvironment
}

\author{
Gayathri Heenatigala Palliyage $^{\mathrm{a}}$, Rajib Ghosh ${ }^{\mathrm{a}}$, Yon Rojanasakul ${ }^{\mathrm{a}, \mathrm{b}, *}$ \\ a Department of Pharmaceutical Sciences, West Virginia University, Morgantown, WV 26506 USA \\ b Mary Babb Randolph Cancer Center, West Virginia University Cancer Institute, Morgantown, WV 26506 \\ USA
}

*Corresponding author, e-mail: yrojan@hsc.wvu.edu

Received 5 Sep 2020

Accepted 4 Nov 2020

\begin{abstract}
Anticancer drug resistance, also known as a chemoresistance, continues to be the greatest challenge in cancer therapies. Chemoresistance is acquired during cancer treatment due to several mechanisms such as genetic alterations in the drug target, drug inactivation, and increased drug efflux from cancer cells. Therefore, a cure for cancer is challenging for most patients. The current focus on cancer research needs to be re-evaluated to resolve this issue. In recent years, many efforts have been devoted to understanding the interactions between malignant and non-malignant cells in the tumor microenvironment (TME) during cancer progression and treatment. Several TMEtargeted therapeutic strategies have been developed and utilized in clinical applications due to an increased recognition of TME as a key driver of tumor progression and chemoresistance. An additional challenge to effective cancer therapy is targeted delivery of therapeutic agents to the tumor site without harming surrounding healthy tissues and organs. The therapeutic efficacy of anticancer drugs is significantly hindered by non-specific biodistribution and low bioavailability of the drugs at tumor sites. In this regard, nanomedicines, including nanoparticle-based drug delivery systems, have been employed to improve the safety and efficacy of cancer therapeutics via TME targeting. This review provides a summary of the cellular components of TME, their roles in cancer progression and chemoresistance, and various TME-targeted therapeutic strategies and clinical trials.
\end{abstract}

KEYWORDS: cancer, chemoresistance, tumor microenvironment, nanomedicine

\section{INTRODUCTION}

Cancer is a leading cause of death worldwide. In 2020, an estimated 1.8 million new cancer cases and 606520 cancer deaths are expected in the United States. The cancer incidence is projected to increase by $45 \%$ from 2010 to 2030 [1]. To cope with this surge, a wide variety of cancer treatment strategies, including surgery, radiation therapy, chemotherapy, and more recently targeted therapy and immunotherapy, have been used to keep cancer under control. However, chemotherapy remains the most common type of cancer treatments. And while cancer chemotherapy is expected to have high efficacy, approximately $97 \%$ of new anticancer drugs fail in clinical trials due to lack of efficacy and/or safety issues [2].

Chemoresistance is one of the leading causes of cancer treatment failure and is responsible for most of cancer-related deaths. Chemoresistance is a complex phenomenon caused by several host and tumor-related factors such as drug target mutations, genetic and epigenetic alterations, DNA damage repair, cell death inhibition, and drug inactivation [3]. There remains an urgent need to focus on developing new therapies to reduce the failure in clinical trials. Tumors have been traditionally believed to be clonal. Intratumoral genetic heterogeneity is observed across many cancers and is recognized as a key contributor to chemotherapy resistance and poor prognosis in cancer patients [4]. Therefore, a deeper understanding of the mechanisms underlying tumor heterogeneity and chemoresistance is critically needed.

Recent studies have begun to focus on targeting the tumor microenvironment (TME) as a novel treatment approach since the traditional approach of targeting tumor cells alone has not achieved a successful outcome. The physiochemical characteristics (e.g., hypoxia and low $\mathrm{pH}$ ) of TME and its heterogeneous cell population, including stromal cells, blood vessel cells, and immune cells are potential targets for novel anticancer therapies. The intent of this review is to summarize existing knowledge 
on the TME, its composition and key cellular constituents, as well as their roles and potential interventions in tumor progression and chemoresistance. Additionally, we will discuss different mechanisms of chemoresistance in order to provide some understanding of the possible causes of chemotherapy failure and tumor relapse. We will also review current therapeutic strategies and nanoparticle-based drug targeting strategies to overcome these limitations.

\section{COMPOSITION OF THE TUMOR MICROENVIRONMENT}

Tumor is a highly complex tissue encircled by extracellular matrix (ECM) and stromal cells [5]. The complex functional ecosystem in which cellular and non-cellular components reside and interact is defined as the TME. It comprises of proliferating tumor cells, stromal cells (e.g., cancer-associated fibroblasts, blood vessel cells, lymphatic endothelial cells), infiltrating inflammatory cells, and a variety of myeloid cells such as dendritic cells and macrophages. The major cellular components of TME are summarized in Fig. 1. Increasing evidence indicates the essential roles of these TME cells in tumor initiation, progression and metastasis [5]. The following sections will summarize key cellular players of the TME, including cancer-associated fibroblasts, inflammatory cells, blood and ECM that are involved in tumor progression and chemoresistance.

\section{Cancer-associated fibroblasts}

Cancer-associated fibroblasts (CAFs), the most dominant component of TME, are a subpopulation of fibroblasts having a similar phenotype as myofibroblasts. The spindle-shaped CAFs play a vital role in remodeling ECM of TME. However, the origin, subtypes and functions of CAFs are not fully understood due to their heterogeneity and absence of specific markers [6]. The potential origins of CAFs are normal fibroblasts, mesenchymal cells, endothelial cells, and epithelial cells. Several studies have been carried out to identify CAF markers, including $\alpha$ smooth muscle actin ( $\alpha$-SMA), fibroblast-activated protein-a (FAP-a), podoplanin (PDPN), desmin, integrin $\beta$, and neuron glial antigen (NG2) $[7,8]$. CAFs produce more collagen and other ECM proteins as well as pro-tumor factors than normal fibroblasts. In wound repair, myofibroblasts are transiently activated; they either undergo apoptosis or revert to the original fibroblast phenotype. Unlike the normal process of wound healing, CAFs present at the tumor site are perpetually activated, resulting in growth and invasion of the tumor cells. A number of studies have revealed that tumor initiation and growth depend on the activation of CAFs $[8,9]$. For example, activation of CAFs by carbon nanomaterials was shown by our group to promote tumor growth caused by existing lung tumor cells and nanomaterial-induced neoplastic cells [8]. Inhibition of CAFs by genetic ablation of PDPN, a CAF biomarker, was also shown to abrogate CAF-induced tumor promotion and reduce cancer stem cell (CSC) population in the tumor mass [8]. Since CSCs are known to be a key driver of tumor metastasis and chemoresistance [10], these results suggest that CAFs may have a broader role in tumor progression and chemotherapy resistance than originally thought. The results also suggest that CAFs and specifically PDPN could be a potential therapeutic target for cancer treatment.

\section{Immune cells}

The immune system plays a critical role in defending the body against invading or infectious agents. However, the composition of immune cells and their abundancy vary significantly with disease progression and prognostic factors [11]. Immune cells from both innate and adaptive immune systems are recruited to the TME. Helper T cells (CD4+) and cytotoxic $\mathrm{T}$ cells $(\mathrm{CD} 8+)$ are two major types of $\mathrm{T}$ cells [12]. Antigen-experienced (CD8+) T cells and memory (CD45RO+) $\mathrm{T}$ cells are excellent prognostic indicators due to their ability to kill tumor cells selectively. Interleukin-2 (IL-2), interferon- $\gamma$ (IFN- $\gamma$ ), and tumor necrosis factor- $\beta$ (TNF- $\beta$ ) are pro-inflammatory cytokines that are produced by CD4+ T helper 1 (Th1) cells. The high density of these cells in the TME correlates with a good prognosis [13].

$B$ cells infiltrating the tumor tissues, also known as tumor-infiltrating B (TIB) cells, are mostly found in tertiary lymphoid tissues adjacent to the TME. However, the importance of TIB cells in regulating anti-tumor immunity and tumor progression is still a matter of debate. TIB cells are generally thought to promote anti-tumor immune responses. It has now been suggested that TIB cells are associated with improved clinical outcomes and survival in HER2+ and triple-negative breast cancer patients [14].

\section{Vascular cells}

Tumors are surrounded by a complex vascular network to provide nutrients and oxygen, and to evacuate carbon dioxide and metabolic waste from tumor cells to maintain sustainable growth and sur- 


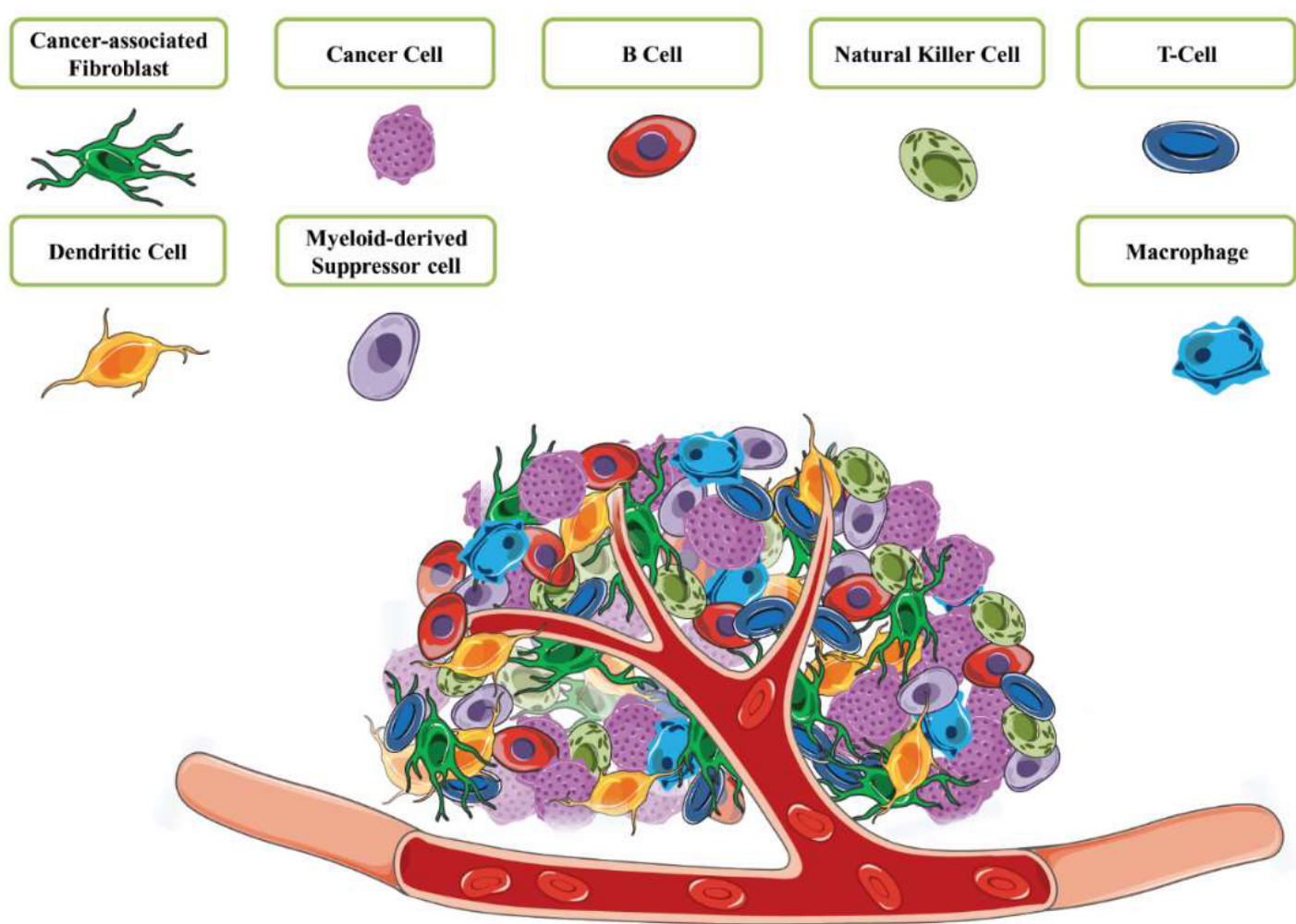

Fig. 1 Major components of the tumor microenvironment.

vival [15]. Tumor vascular network is irregularly distributed in the TME and inefficient in many ways, i.e., it is fragile, tortuous, and extremely leaky/permeable. Also, the angiogenic switch remains almost always turned on during tumor progression, resulting in tumor promoting vasculature [16]. A variety of pro- and anti-angiogenic growth factors secreted by stromal cells and myeloid cells initiate tumor vascularization by accessing the blood vessels from surrounding stroma.

Vascular endothelial growth factor (VEGF), also known as vascular permeability factor (VPF), is a potent angiogenic factor that promotes neovascularization. An overexpression of VEGF is observed in a variety of cancers, including breast, lung, kidney, bladder and ovarian cancer [17]. In addition to VEGF, platelet-derived growth factor (PDGF), transforming growth factor (TGF), fibroblast growth factor (FGF), and tumor necrosis factor (TNF) are some of the pro-angiogenic factors associated with tumor angiogenesis. In particular, FGF signaling which is mediated by two major oncogenic pathways, phosphatidylinositol 3-kinase/Akt (PI3K/Akt) and mitogen-activated protein kinases (MAPK), promotes angiogenesis [18].

\section{Tumor-associated macrophages}

Tumor-associated macrophages (TAMs) are often the principal constituent of TME in solid tumors and account for up to $50 \%$ of tumor mass [19]. TAMs perform diverse functions in tumor growth, immune regulation, tumor angiogenesis, metastasis and chemoresistance. Macrophages are broadly categorized as M1 (classical-activated macrophages) and M2 (alternative-activated macrophages) depending on their phenotype. Both phenotypes play contrasting roles in tumor pathogenesis and evolution. M1 macrophages play an anti-tumorigenic role, while M2 macrophages are pro-tumorigenic. An increasing number of studies have revealed that TAMs exhibit the M2 phenotype [20]. M2 macrophages are characterized by secretion of antiinflammatory cytokines such as IL-4, IL-10 and IL13 , which play a critical role in tissue repair and tumor progression [20].

\section{MECHANISMS OF CHEMORESISTANCE}

Chemotherapy is a type of cancer treatment that utilizes chemical drugs to kill rapidly growing cancer cells. However, chemoresistance, the insensitivity of cancer cells to the drugs, develops and is the leading 
cause of failure in cancer chemotherapy. The underlying mechanisms of cancer chemoresistance are incompletely understood [21]. Hence, understanding the relationship between cancer progression and chemoresistance in response to chemotherapy is essential to successful development of novel anticancer therapeutics. Drug resistance can be intrinsic (pre-existent) or acquired (drug-induced). Intrinsic resistance indicates the lack of tumor response to initial therapy due to pre-existent resistance in cancer cells. Mutational changes in cancer cells during chemotherapy make them insensitive to the treatment leading to acquired resistance [22].

\section{Cancer stem cells}

Cancer stem cells (CSCs), also known as tumorinitiating cells (TICs), are thought to play an important role in metastatic relapse and chemoresistance as a result of their ability to self-renew and differentiate into heterogeneous tumor cells [23]. In addition to chemotherapeutic agents, other exogenous agents such as high aspect ratio nanomaterials and asbestos fibers have been shown to induce CSCs that contribuite to their carcinogenicity [24-26]. The mechanisms by which these agents regulate CSCs are incompletely understood and are likely to be agent specific. However, an alteration in selfrenewal transcription factors that control stemness of cancer cells has been suggested as a common mechanism of CSC regulation. In this regard, we have recently identified SOX9-ALDH regulatory axis as a master regulator of CSCs in chemoresist lung cancer [10]. SOX9 is a transcription factor that is upregulated in chemoresistant cancer cells and its expression level correlates with poor overall survival in cancer patients. We found that SOX-9 positively regulates CSCs through transcriptional activation of aldehyde dehydrogenase (ALDH), which is responsible for chemoresistance in lung cancer cells [10]. Regulation of CSCs during chemoresistance can also occur post-transcriptionally and is dependent on cellular conditions and TME. For example, we have found that cellular oxidative and nitrosative stress play a critical role in chemotherapy resistance and CSC regulation in leukemia cells and lung cancer cells [27-30].

Chemoresistance is also driven by inadequate bio-accessibility of the drugs to tumor tissues. Vast distances between blood vessels, high interstitial fluid pressure, and irregular vascular network contribute to poor drug distribution in solid tumors. Hence, tumor cells located distally from blood vessels are exposed to ineffective drug concentra- tion [31]. As resistance develops within the tumor population, cancer cells escape from apoptosis resulting in tumor cells becoming insensitive to the drugs that were once effective. There are many mechanisms that contribute to chemoresistance, including alterations in drug efflux, DNA damage repair, epithelial-mesenchymal transition (EMT), cell death inhibition, drug target alteration, and drug activation (Fig. 2). Table 1 summarizes some known chemoresistance mechanisms of commonly used anticancer drugs.

\section{Drug efflux mechanisms}

Cancer cells achieve chemoresistance by activating ATP binding cassette (ABC) transporters, also known as drug efflux mechanisms. These are the most abundant transmembrane proteins which can shuttle drugs, metabolic products, and foreign substances through the cell membrane using energy derived from ATP hydrolysis [32]. An overexpression of specific $A B C$ transporter proteins is often associated with chemoresistance in various solid tumors.

Three major types of $A B C$ proteins involved in chemoresistance have been described, including Pglycoprotein (ABCB1)/multidrug resistance protein 1 (MDR1), multidrug resistance-associated protein 1 (MRP1/ABCC1), and breast cancer resistance protein (BCRP/ABCG2) [48]. BCRP is operated as an efflux pump for small molecule drugs. BCRPassociated resistance has been observed in breast cancer and leukemia [49]. MDR1 is associated with drug resistance in the kidney, liver, breast, lung, colon, and blood cancer. MRP1 is identified as a biomarker for the prediction of chemoresistance. The common anticancer drugs that are known to increase the expression of efflux pumps in cancer cells are cisplatin, doxorubicin, etoposide, estramustine, and vinblastine [50].

\section{Epithelial-mesenchymal transition}

Epithelial-mesenchymal transition (EMT) is a process in which cells can transition from an epithelial phenotype to a mesenchymal phenotype. Epithelial cells are characterized by tight cell-cell junctions and cell polarity. The cellular phenotype changes in epithelial cells facilitate the fibroblastlike morphology resulting in increased cell migration and invasion, and resistance to apoptosis [51]. EMT also plays a role in cancer metastasis and is associated with CSC phenotype. Mani and coworkers showed that human mammary epithelial cells that have undergone EMT exhibited similar 


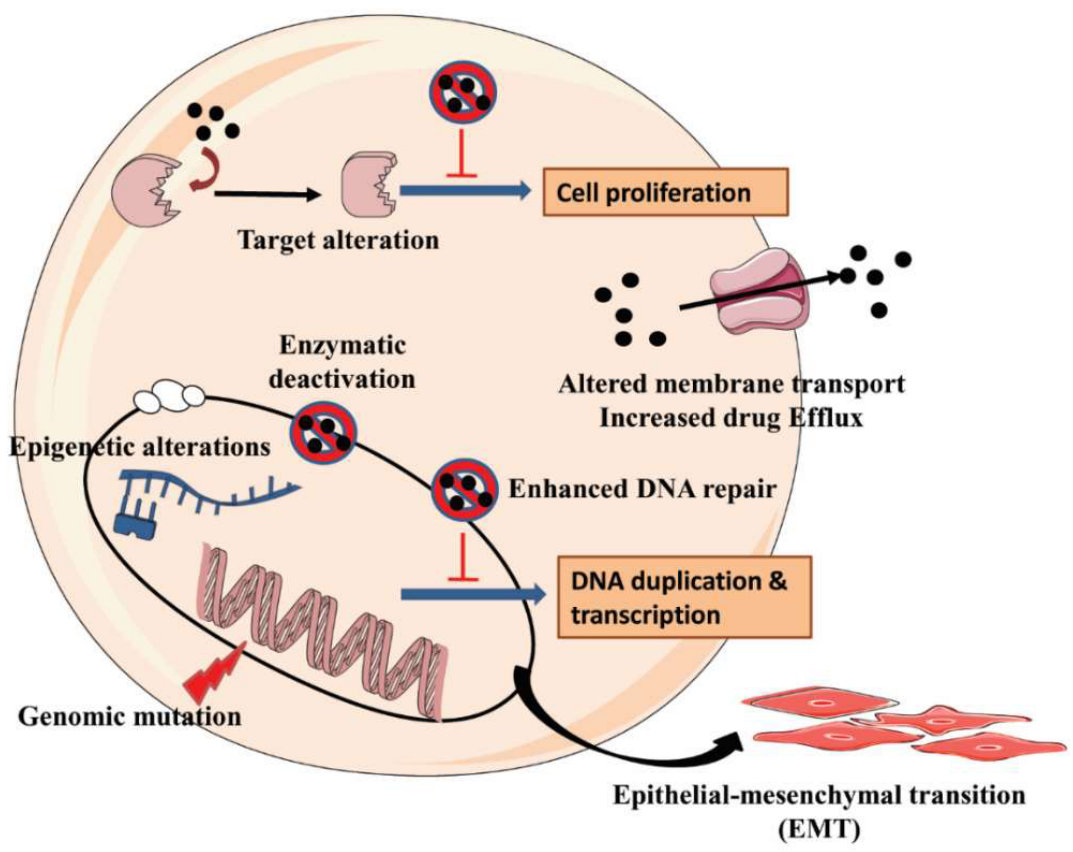

Fig. 2 Mechanisms of chemoresistance in cancer cells.

Table 1 Mechanisms of chemoresistance in cancer therapy.

\begin{tabular}{|c|c|c|c|c|}
\hline \multicolumn{2}{|c|}{ Chemoresistance mechanism } & \multirow{2}{*}{$\begin{array}{l}\text { Targeted } \\
\text { therapy }\end{array}$} & \multirow{2}{*}{$\begin{array}{l}\text { Tumor type } \\
\text { Ovarian cancer }\end{array}$} & \multirow{2}{*}{$\begin{array}{l}\text { Ref. } \\
{[33]}\end{array}$} \\
\hline Drug efflux & ABCF2 & & & \\
\hline & $\mathrm{ABCC} 10$ & 5-Fluorouracil & Colorectal cancer & {$[34]$} \\
\hline \multirow[t]{2}{*}{$\begin{array}{l}\text { DNA dam- } \\
\text { age repair }\end{array}$} & $\begin{array}{l}\text { Mismatch repair (MMR), Nucleotide excision re- } \\
\text { pair (NER), Double-strand break repair (DSB) }\end{array}$ & Cisplatin & Lung cancer & [35] \\
\hline & Double-strand break repair (DSB) by ERCC1 & Cisplatin & Non-small cell lung cancer & [36] \\
\hline \multirow[t]{2}{*}{ EMT } & $\begin{array}{l}\text { Increased vimentin expression, Decreased desmo- } \\
\text { some and tight junction formation }\end{array}$ & Adriamycin & Breast cancer & [37] \\
\hline & $\begin{array}{l}\text { Expression of a transcriptional repressor of E- } \\
\text { cadherin (Zeb-1), Expression of other epithelial } \\
\text { markers (EVA1, MAL2) }\end{array}$ & $\begin{array}{l}\text { Gemcitabine } \\
\text { 5-Fluorouracil } \\
\text { Cisplatin }\end{array}$ & Pancreatic cancer & {$[38]$} \\
\hline \multirow[t]{3}{*}{$\begin{array}{l}\text { Drug target } \\
\text { alteration }\end{array}$} & $\begin{array}{l}\text { Mutations of epidermal growth factor receptor } \\
\text { (EGFR) }\end{array}$ & Gefitinib & Non-small cell lung cancer & [39] \\
\hline & Mutation and amplification of BCR-ABL1 gene & Abl TKI STI-571 & Chronic myeloid leukemia & [40] \\
\hline & Increased expression of microRNAs (miRNAs) & 5-Fluorouracil & Colorectal cancer & {$[41]$} \\
\hline \multirow{3}{*}{$\begin{array}{l}\text { Drug } \\
\text { inactivation }\end{array}$} & Inactivation of Trp53 and Pten & Abiraterone & Prostate cancer & [42] \\
\hline & $\begin{array}{l}\text { DNA methylation of UGT1A1-metabolizing en- } \\
\text { zyme }\end{array}$ & Irinotecan & Colon Cancer & [43] \\
\hline & $\begin{array}{l}\text { Methylation of ECGF-1 resulting in transcriptional } \\
\text { silencing of TP }\end{array}$ & Capecitabine & Mesothelioma & [44] \\
\hline \multirow[t]{3}{*}{ Epigenetics } & hMLH1 promoter hypermethylation & 5-Fluorouracil & Colorectal Cancer & [45] \\
\hline & $\begin{array}{l}\text { Methylation of a } \mathrm{CpG} \text { island in the RFC gene } \\
\text { promoter region }\end{array}$ & Methotrexate & Breast Cancer & [46] \\
\hline & Hypermethylation of MGMT promoter & Fotemustine & Melanoma & [47] \\
\hline
\end{tabular}

ABC: ABC transporters, ERCC1: excision repair cross-complementation group 1 protein, TP: thymidine phosphorylase, ECGF: extracellular growth factor-1, MGMT: O(6)-methylguanine-DNA methyltransferases, TKI: tyrosine kinase inhibitor. 
traits to CSCs derived from normal and neoplastic mammary stem-like cells [52]. In lung cancer cells, our group showed that EMT is functionally linked to CSCs as downregulation of E-cadherin, an EMT marker, promoted EMT and increased stemness of the cells [53]. Such downregulation also promoted cell death resistance and invasiveness of the cells [53]. The mechanism by which EMT regulates CSCs in lung cancer cells was shown to involve mesothelin (MSLN) activation [54]. MSLN is a tumor-associated antigen that is overexpressed on various malignant tumor cells. Knockdown of MSLN was found to reverse EMT and attenuate stemness of lung cancer cells in addition to inhibiting tumor growth and metastasis [54]. EMT activation is also associated with chemotherapy resistance allowing epithelial cells to escape from drug treatment and various endogeneous and exogenous cellular stresses, including hypoxia, nutrient depletion, and mechanical constraint [55]. Many studies have shown a strong relationship between EMT phenotype and chemotherapy resistance. For example, doxorubicin resistance is developed in breast cancer cells undergoing EMT [56].

\section{Drug inactivation}

The anticancer efficiency of a drug can be diminished via the process of inactivation. Some types of cells (e.g., liver cells) are highly resistant to drugs. The enzyme called cytochrome P450 present in liver cells can effectively detoxify drugs in the cytoplasm [41]. The dihydropyrimidine dehydrogenase (DPD) enzyme is responsible for the catabolism of antimetabolite drugs such as 5-fluorouracil (5FU) and methotrexate, mainly in the liver cells. The antimetabolite drugs must undergo chemical conversion within the cells before exerting their therapeutic effect. However, such conversion is inhibited by the absence or impairment of DPD enzyme [57]. Furthermore, DPD overexpression in cancer cells has been linked to resistance to 5-FU. The thiolcontaining tripeptide glutathione (GSH) is a powerful antioxidant abundantly presented in all cells. Many studies have revealed the correlation between intracellular GSH level and cisplatin resistance in various cell lines [58]. GSH has also been shown to inactivate cisplatin by binding covalently through its highly reactive thiol group. Such inactivation leads to increased cisplatin detoxification and drug efflux, and prevents the drug from reacting with DNA and other intracellular targets [59].

\section{DNA repair mechanisms}

Most chemotherapeutic agents kill tumor cells by damaging their DNA, either directly or indirectly. Cells have multiple repair mechanisms to deal with the damaging effect, including ROS scavenging, ataxia telangiectasia mutated (ATM) kinase and checkpoint kinase $1 / 2$ (Chk1/Chk2) activation, and anti-apoptotic signaling via Wnt $/ \beta$-catenin, Notch, and PI3K/Akt pathways [8]. It is crucial to maintain the steady intracellular levels of ROS under normal physiological conditions in tumor cells in order to promote cell growth and disable cell death mechanisms. Excessive ROS production can lead to oxidative stress, which is defined as a condition where the rate of ROS production exceeds the capability of antioxidant defense mechanisms [60]. Elevated ROS levels can damage biomolecules, including DNA, proteins and lipids, resulting in cancer cell senescence and apoptosis. The existence of enhanced adaptive stress strategies selectively protects cancer cells from ROS-mediated DNA damage leading to chemoresistance [61].

\section{Drug target alterations}

The efficacy of an anticancer drug is dependent on its molecular target and an alteration of such target through gene mutation or dysregulated expression, leading to drug resistance. For example, topoisomerase II (Top2) disentangles strands of DNA helix to inhibit DNA entanglement and supercoiling. Top2 mutations ead to cancer cell resistance against Top2 inhibitors such as etoposide and doxorubicin [62]. Certain mutations in protein kinases are also a major cause of drug resistance. Epidermal growth factor receptor (EGFR) inhibitors such as gefitinib and erlotinib are commonly used in targeted therapy of non-small-cell lung cancer (NSCLC) to inhibit EGFR's kinase activity. EGFR mutation (in-frame deletion in exon 19) leads to acquired resistance to EGFR inhibitors [63]. An overexpression of human epidermal growth factor receptor 2 (HER2) has been reported in $20-30 \%$ of breast cancer patients. Trastuzumab, an anti-HER2 monoclonal antibody, is commonly used in breast cancer patients to inhibit cancer cell growth. Several breast cancer patients were reported to have tumor progression despite trastuzumab therapy due to drug resistance caused by HER2 amplification [64].

\section{Epigenetic alterations}

Epigenetic alterations have been recognized as an important factor in chemoresistance. Epigenetic 
mechanisms, mainly DNA methylation and histone modification, play a crucial role in regulating gene expression and cell differentiation [65]. Cytosine in CpG islands of DNA is frequently methylated to 5methylcytosine $(5 \mathrm{mC})$ by DNA methyltransferases. Hypermethylation of $\mathrm{CpG}$ islands causes genomic instability leading to tumor suppressor gene silencing. Hypermethylation of secreted frizzled-related protein 5 (SFRP5) gene that acts as a Wnt antagonist in ovarian cancer has been shown to be associated with platinum resistance [66]. Histone modifications, including acetylation and deacetylation, take place on the lysine residues located at the N-terminal of histones and non-histone proteins. Histone acetyltransferases (HATs) and histone deacetylases (HDACs) are the two opposing classes of enzymes that catalyze the aforementioned reactions, respectively [67].

\section{THERAPEUTIC STRATEGIES TARGETING TUMOR MICROENVIRONMENT}

The efficacy of anticancer drugs is limited by several factors including inefficient distribution of drugs to target tissues or organs, limited drug penetration into tumor mass, and drug degradation. Nanomedicine is emerging as a promising therapeutic platform that utilizes nano-sized drug delivery carriers to increase the therapeutic index of chemotherapeutic agents by improving their delivery to the tumor site [68]. However, TME is structurally complex and highly disorganized with an uneven distribution of blood vessels that limits the distribution of nanoparticles within the TME [69]. There is a need to improve the efficiency of drug delivery and design more effective drug delivery systems to overcome such barriers created by the solid tumors. Therefore, the unique characteristics of TME, such as hypoxia, acidic $\mathrm{pH}$, high enzymatic activity, and specific TME markers should be taken into consideration when designing new drug delivery systems for cancer treatment (Fig. 3).

\section{Acidic tumor microenvironment}

The acidic environment of TME ( $\mathrm{pH}$ 6-7 range) has been widely utilized to enhance drug release from nanoparticles by triggering $\mathrm{pH}$-dependent structural transformation of the nanoparticles. Nanoparticles are generally stable at the extracellular $\mathrm{pH}(\sim 7.4)$ of normal tissues and blood, whereas they are gradually dissociated at the extracellular $\mathrm{pH}(6.0-7.0)$ of solid tumors due to protonation of $\mathrm{pH}$-sensitive moieties present on them. Acid-sensitive linkers or ionizable groups are commonly used $\mathrm{pH}$-sensitive moieties for TME drug delivery and targeting [70]. Acid-soluble inorganic nanoparticles have increasingly been used in many cancer chemotherapy applications because of their tunable physicochemical properties. Dong and co-workers developed monodispersed calcium carbonate nanoparticles modified with polyethylene glycol (PEG) to incorporate $\mathrm{Mn}^{2+}$-chelated chlorin e6 (Ce6(Mn)) and doxorubicin (DOX) for cancer therapy [71]. This delivery system is rapidly dissociated at a mild acidic environment (pH 6.5-5.5) and effectively releases both DOX and Ce6(Mn) at the tumor site.

\section{Hypoxia}

It has been shown that tumor hypoxia plays a significant role in tumorigenesis and drug resistance. Tumor hypoxia, also known as a deprivation of oxygen in tumor cells, is proven to be a pivotal driver of neovascularization and EMT, which facilitate rapid tumor growth [72]. Hypoxic tumor cells are located at a distance from blood vessels, making them less responsive to chemotherapeutic agents [73]. As a result, hypoxic cells are substantially more resistant to chemotherapy or radiotherapy. Increasing research efforts have been devoted to improving tumor oxygenation. Yang's group reported $\mathrm{pH}$ responsive catalase (CAT) and Ce6 hollow silica nanoparticles capable of light-triggered ROS generation [74]. CAT-loaded nanoparticles were rapdly degraded in the acidic environment of TME and induced tissue oxygenation by converting $\mathrm{H}_{2} \mathrm{O}_{2}$ into $\mathrm{H}_{2} \mathrm{O}$ and $\mathrm{O}_{2}$ via CAT-mediated enzymatic reaction.

\section{Targeting neoplastic vs. TME cells}

Over the past decades, cancers have been mistakenly identified as a mono-cellular disorder, and most approved anticancer drugs target neoplastic cells [75]. Limitation of such approach and an increasing recognition of the role of TME in cancer progression and chemoresistance have led to a new focus on TME cells, such as CAFs and TAMs. Nanoparticles have been used to overcome the penetration limitation by selectively targeting CAFassocaited proteins, such as $\alpha$-SMA and FAP- $\alpha$ [76]. Cleavable amphiphilic peptide nanoparticles (CAPNPs) were designed to be specifically responsive to FAP- $\alpha$. Drug-loaded CAP-NPs rapidly dissembled upon cleavage of FAP- $\alpha$ that resulted in efficient drug release and deep tumor penetration [77].

Most macrophage-targeted therapies are mainly focused on limiting macrophage recruitment, depleting TAMs, initiating immune responses, and blocking TAM-mediated tumor promotion [78]. 


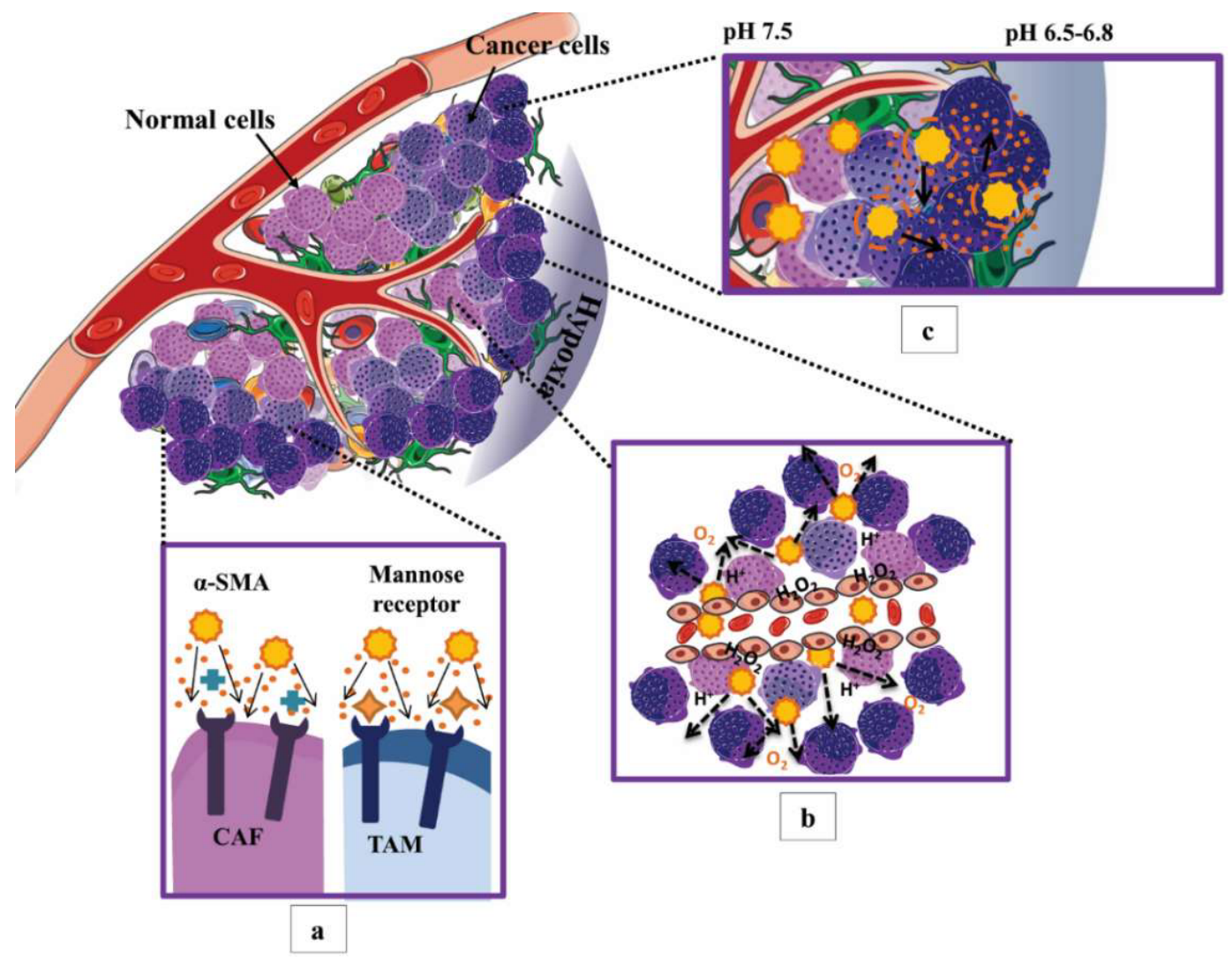

Fig. 3 Nanomedicine based therapeutic strategies to target tumor microenvironment: a. composition of TME targeted nanoparticles (i.e., CAFs and TAMs), b. nanoparticle activation by hypoxia, c. nanoparticle activation by acidic $\mathrm{pH}$.

Receptor-mediated endocytosis is often used as a means to target TAMs for drug delivery. TAM surface markers, such as mannose receptor, folate receptor, galactose receptor, legumain, and CD163 receptor have been explored for macrophage-targeted therapies [65]. Huang and co-workers developed acidsensitive, galactosylated cationic nanoparticles to deliver oligonucleotides (CpG, anti-IL-10, and antiIL-10R) to suppress pro-tumor functions and initiate anti-tumor activities of TAMs. The results showed that the galactosylated nanoparticles were able to target TAMs by binding to galactosylated lectin moieties on the cell surface [79].

\section{FINAL NOTE}

Chemoresistance continues to be the leading cause of failure in cancer chemotherapy. Therefore, new knowledge is critically needed to improve our understanding of the drug resistance problem and identify new drug targets for more effective treatment of cancers. This review provides an overview of the composition of TME, its roles in tumor progression and chemoresistance, as well as its ex- ploitation as therapeutic and drug delivery targets. In recent years, several therapeutic strategies including small molecule and antibody-based therapeutics have been developed to target the TME. It is likely that other therapeutic strategies such as siRNA, miRNA and other gene-based therapeutics will be developed for advanced cancer treatments. Such development will require effective drug delivery systems that target the TME. By exploiting the unique features of TME, i.e., hypoxia, acidic $\mathrm{pH}$, and redox status, as well as specific surface markers of TME cells, such targeting is feasible and several nanoparticle-based drug delivery systems have been developed for such purpose. Thus, nanomedicine is promised to revolutionize the field of cancer therapy by improving drug targeting ability and minimizing chemoresistance and relapse.

\section{REFERENCES}

1. WHO (2020) Cancer, World Health Organization. Available at: www.who.int/cancer/resources/ keyfacts/en. 
2. Wong C, Siah K, Lo A (2018) Corrigendum: Estimation of clinical trial success rates and related parameters. Biostatistics 20, 273-286.

3. Hasan S, Taha R, Omri HE (2018) Current opinions on chemoresistance: An overview. Bioinformation $14,80-85$.

4. Laajala TD, Gerke T, Tyekucheva S, Costello JC (2019) Modeling genetic heterogeneity of drug response and resistance in cancer. Curr Opin Syst Biol 17, 8-14.

5. Yuan Y, Jiang YC, Sun CK, Chen QM (2016) Role of the tumor microenvironment in tumor progression and the clinical applications (Review). Oncol Rep 35, 2499-2515.

6. Chen X, Song E (2019) Turning foes to friends: targeting cancer-associated fibroblasts. Nat Rev Drug Discov 18, 99-115.

7. Turley SJ, Cremasco V, Astarita JL (2015) Immunological hallmarks of stromal cells in the tumour microenvironment. Nat Rev Immunol 15, 669-682.

8. Luanpitpong S, Wang L, Castranova V, Dinu CZ, Issaragrisil S, Chen YC, Rojanasakul Y (2016) Induction of cancer-associated fibroblasts by carbon nanotubes dictates its tumorigenicity. Sci Rep 6, ID 39558.

9. Orimo A, Gupta PB, Sgroi DC, Arenzana-Seisdedos F, Delaunay T, Naeem R, Carey VJ, Richardson AL, et al (2005) Stromal fibroblasts present in invasive human breast carcinomas promote tumor growth and angiogenesis through elevated SDF-1/CXCL12 secretion. Cell 121, 335-348.

10. Voronkova MA, Rojanasakul LW, Kiratipaiboon C, Rojanasakul Y (2020) SOX9-ALDH axis determines resistance to chemotherapy in non-small cell lung cancer. Mol Cell Biol 40, e0030719.

11. Mlecnik B, Bindea G, Kirilovsky A, Angell HK, Obenauf AC, Tosolini M, Church SE, Maby P, et al (2016) The tumor microenvironment and immunoscore are critical determinants of dissemination to distant metastasis. Sci Transl Med 8, 327-326.

12. Manser AR, Uhrberg M (2016) Age-related changes in natural killer cell repertoires: impact on NK cell function and immune surveillance. Cancer Immunol Immunother 65, 417-426.

13. Fridman WH, Pagès F, Sautès-Fridman C, Galon J (2012) The immune contexture in human tumours: impact on clinical outcome. Nat Rev Cancer 12, 298-306.

14. Garaud S, Buisseret L, Solinas C, Gu-Trantien C, de Wind A, Van den Eynden G, Naveaux C, Lodewyckx JN, et al (2019) Tumor infiltrating B-cells signal functional humoral immune responses in breast cancer. JCI Insight 5, e129641.

15. De Bock K, Cauwenberghs S, Carmeliet P (2011) Vessel abnormalization: another hallmark of cancer? Molecular mechanisms and therapeutic implications. Curr Opin Genet Dev 21, 73-79.
16. Bergers G, Benjamin LE (2003) Tumorigenesis and the angiogenic switch. Nat Rev Cancer 3, 401-410.

17. Olson TA, Mohanraj D, Carson LF, Ramakrishnan S (1994) Vascular permeability factor gene expression in normal and neoplastic human ovaries. Cancer Res 54, 276-280.

18. Gavalas NG, Liontos M, Trachana SP, Bagratuni T, Arapinis C, Liacos C, Dimopoulos M, Bamias A (2013) Angiogenesis-related pathways in the pathogenesis of ovarian cancer. Int $J$ Mol Sci 14, 15885-15909.

19. Guo Q, Jin Z, Yuan Y, Liu R, Xu T, Wei H, Xu X, He $S$, et al (2018) Corrigendum to "New mechanisms of tumor-associated macrophages on promoting tumor progression: Recent research advances and potential targets for tumor immunotherapy". J Immunol Res 2018, ID 6728474.

20. Sica A, Larghi P, Mancino A, Rubino L, Porta C, Totaro MG, Mantovani A, Allavena P, et al (2008) Macrophage polarization in tumour progression. Semin Cancer Biol 18, 349-355.

21. Brasseur K, Gévry N, Asselin E (2017) Chemoresistance and targeted therapies in ovarian and endometrial cancers. Oncotarget 8, 4008-4042.

22. Longley D, Johnston P (2005) Molecular mechanisms of drug resistance. J Pathol 205, 275-292.

23. Sun Z, Wang L, Dong L, Wang X (2018) Emerging role of exosome signalling in maintaining cancer stem cell dynamic equilibrium. $J$ Cell Mol Med 22, 3719-3728.

24. Luanpitpong S, Wang L, Castranova V, Rojanasakul Y (2014) Induction of stem-like cells with malignant properties by chronic exposure of human lung epithelial cells to single-walled carbon nanotubes. Part Fibre Toxicol 11, ID 22.

25. Luanpitpong S, Li J, Manke A, Brundage K, Ellis E, McLaughlin SL, Angsutararux P, Chanthra N, et al (2016) SLUG is required for SOX9 stabilization and functions to promote cancer stem cells and metastasis in human lung carcinoma. Oncogene 35, 2824-2833.

26. Voronkova MA, Luanpitpong S, Wang L, Castranova V, Dinu CZ, Riedel H, Rojanasakul Y (2017) SOX9 regulates cancer stem-like properties and metastatic potential of single-walled carbon nanotube-exposed cells. Sci Rep 7, ID 11653.

27. Luanpitpong L, Poohadsuan J, Samart P, Kiratipaiboon C, Rojanasakul Y, Issaragrisil S (2018) Reactive oxygen species mediate cancer stem-like cells and determine bortezomib sensitivity via Mcl-1 and Zeb-1 in mantle cell lymphoma. Biochim Biophys Acta 1864, 3739-3753.

28. Maiuthed A, Bhummaphan N, Luanpitpong S, Mutirangura A, Aporntewan C, Meeprasert A, Rungrotmongkol T, Rojanasakul Y, et al (2018) Nitric oxide promotes cancer cell dedifferentiation by disrupting an Oct4: caveolin-1 complex: A new regulatory 
mechanism for cancer stem cell formation. $J$ Biol Chem 293, 13534-13552.

29. Yongsanguanchai N, Pongrakhananon V, Mutirangura A, Aporntewan C, Rojanasakul Y, Chanvorachote $P$ (2015) Nitric oxide induces cancer stem celllike phenotypes in human lung cancer cells. Am $J$ Physiol Cell Physiol 308, C89-C100.

30. Luanpitpong S, Chanthra N, Janan M, Poohadsuan J, Samart P, U-Pratya Y, Rojanasakul Y, Issaragrisil S (2018) Inhibition of O-GlcNAcase sensitizes apoptosis and reverses bortezomib resistance in mantle cell lymphoma through modification of truncated Bid. Mol Cancer Ther 17, 484-496.

31. Zhao J (2016) Cancer stem cells and chemoresistance: The smartest survives the raid. Pharmacol Ther 160, 145-158.

32. Fletcher JI, Haber M, Henderson MJ, Norris MD (2010) ABC transporters in cancer: more than just drug efflux pumps. Nat Rev Cancer 10, 147-156.

33. Seborova K, Vaclavikova R, Soucek P, Elsnerova K, Bartakova A, Cernaj P, Dvorak P, Bouda J, et al (2019) Association of $\mathrm{ABC}$ gene profiles with time to progression and resistance in ovarian cancer revealed by bioinformatics analyses. Cancer Med 8, 606-616.

34. Xie T, Geng J, Wang Y, Wang L, Huang M, Che J, Zhang K, Xue L, et al (2017) FOXM1 evokes 5fluorouracil resistance in colorectal cancer depending on ABCC10. Oncotarget 8, 8574-8589.

35. Yu WK, Wang Z, Fong CC, Liu D, Yip TC, Au K, Zhu G, Yang M (2017) Chemoresistant lung cancer stem cells display high DNA repair capability to remove cisplatin-induced DNA damage. Br J Pharmacol 174, 302-313.

36. Olaussen KA, Dunant A, Fouret P, Brambilla E, André F, Haddad V, Taranchon E, Filipits M, et al (2006) DNA repair by ERCC1 in non-small-cell lung cancer and cisplatin-based adjuvant chemotherapy. $N$ Engl $J$ Med 355, 983-991.

37. Sommers CL, Heckford SE, Skerker JM, Worland P, Torri JA, Thompson EW, Byers SW, Gelmann EP (1992) Loss of epithelial markers and acquisition of vimentin expression in adriamycin- and vinblastineresistant human breast cancer cell lines. Cancer Res 52, 5190-5197.

38. Arumugam T, Ramachandran V, Fournier KF, Wang H, Marquis L, Abbruzzese JL, Gallick GE, Logsdon CD (2009) Epithelial to mesenchymal transition contributes to drug resistance in pancreatic cancer. ancer Res 69, 5820-5828.

39. Kobayashi S, Boggon TJ, Dayaram T, Jänne PA, Kocher O, Meyerson M, Johnson BE, Eck MJ, et al (2005) EGFR mutation and resistance of non-smallcell lung cancer to gefitinib. $N$ Engl $J$ Med 352, 786-792.

40. Gorre ME, Mohammed M, Ellwood K, Hsu N, Paquette R, Rao PN, Sawyers CL (2001) Clinical resistance to STI-571 cancer therapy caused by BCR-ABL gene mutation or amplification. Science 293, 876-880.

41. Du F, Chen J, Liu H, Cai Y, Cao T, Han W, Yi X, Qian M (2019) SOX12 promotes colorectal cancer cell proliferation and metastasis by regulating asparagine synthesis. Cell Death Dis 10, ID 239.

42. Zou M, Le Magnen C, Toivanen R, Mitrofanova A, Hayati S, Floch N, Hayati S, Sun Y, et al (2017) Transdifferentiation as a mechanism of treatment resistance in a mouse model of castration-resistant prostate cancer. Cancer Discov 7, 736-749.

43. Gagnon JF, Bernard O, Villeneuve L, Têtu B, Guillemette C (2006) Irinotecan inactivation is modulated by epigenetic silencing of UGT1A1 in colon cancer. Clin Cancer Res 12, 1850-1858.

44. Kosuri KV, Wu X, Wang L, Villalona-Calero MA, Otterson GA (2010) An epigenetic mechanism for capecitabine resistance in mesothelioma. Biochem Biophys Res Commun 391, 1465-1470.

45. Arnold CN, Goel A, Boland CR (2003) Role of hMLH1 promoter hypermethylation in drug resistance to 5fluorouracil in colorectal cancer cell lines. Int J Cancer 106, 66-73.

46. Worm J, Kirkin AF, Dzhandzhugazyan KN, Guldberg P (2001) Methylation-dependent silencing of the reduced folate carrier gene in inherently methotrexateresistant human breast cancer cells. J Biol Chem 276, 39990-40000.

47. Christmann M, Pick M, Lage H, Schadendorf D, Bern K (2001) Acquired resistance of melanoma cells to the antineoplastic agent fotemustine is caused by reactivation of the DNA repair gene mgmt. Int $J$ Cancer 92, 123-129.

48. Leslie EM, Deeley RG, Cole SPC (2005) Multidrug resistance proteins: role of P-glycoprotein, MRP1, MRP2, and BCRP (ABCG2) in tissue defense. Toxicol Appl Pharmacol 204, 216-237.

49. Doyle LA, Yang W, Abruzzo LV, Krogmann T, Gao Y, Rishi A, Ross DD (1998) A multidrug resistance transporter from human MCF-7 breast cancer cells. Proc Natl Acad Sci USA 95, 15665-15670.

50. Romana-Rea B, Marco F (2017) ABC Transporters in cancer stem cells: beyond chemoresistance. Int $\mathrm{J} \mathrm{Mol}$ Sci 18, ID 2362.

51. Lamouille S, Xu J, Derynck R (2014) Molecular mechanisms of epithelial-mesenchymal transition. Nat Rev Mol Cell Biol 15, 178-196.

52. Mani SA, Guo W, Liao M-J, Eaton EN, Ayyanan A, Zhou AY, Brooks M, Reinhard F, et al (2008) The epithelial-mesenchymal transition generates cells with properties of stem cells. Cell 133, 704-715.

53. Powan P, Luanpitpong S, He X, Rojanasakul Y, Chanvorachote P (2017) Detachment-induced E-cadherin expression promotes 3D tumor spheroid formation but inhibits tumor formation and metastasis of lung cancer cells. Am J Physiol Cell Physiol 313, C556-C566.

54. He X, Wang L, Riedel H, Wang K, Yang Y, Dinu CZ, Ro- 
janasakul Y (2017) Mesothelin promotes epithelialto-mesenchymal transition and tumorigenicity of human lung cancer and mesothelioma cells. Mol Cancer 16, ID 63.

55. Thiery JP, Acloque H, Huang RY, Nieto MA (2009) Epithelial-mesenchymal transitions in development and disease. Cell 139, 871-890.

56. Li J, Liu H, Yu J, Yu H (2015) Chemoresistance to doxorubicin induces epithelial-mesenchymal transition via upregulation of transforming growth factor $\beta$ signaling in HCT116 colon cancer cells. Mol Med Rep 12, 192-198.

57. Schwartz PM, Moir RD, Hyde CM, Turek PJ, Handschumacher RE (1985) Role of uridine phosphorylase in the anabolism of 5-fluorouracil. Biochem Pharmacol 34, 3585-3589.

58. Ikegami Y, Tatebe S, Lin-Lee YC, Xie QW, Ishikawa T, Kuo MT (2000) Induction of MRP1 and gammaglutamylcysteine synthetase gene expression by interleukin 1beta is mediated by nitric oxide-related signalings in human colorectal cancer cells. $J$ Cell Physiol 185, 293-301.

59. Brozovic A, Ambriovic-Ristov A, Osmak M (2010) The relationship between cisplatin-induced reactive oxygen species, glutathione, and BCL-2 and resistance to cisplatin. Crit Rev Toxicol 40, 347-359.

60. Peitzsch C, Kurth I, Kunz-Schughart L, Baumann M, Dubrovska A (2013) Discovery of the cancer stem cell related determinants of radioresistance. Radiother Oncol 108, 378-387.

61. Diehn M, Cho RW, Lobo NA, Kalisky T, Dorie MJ, Kulp AN, Qian D, Lam JS, et al (2009) Association of reactive oxygen species levels and radioresistance in cancer stem cells. Nature 458, 780-783.

62. Housman G, Byler S, Heerboth S, Lapinska K, Longacre M, Snyder N, Sarkar S (2014) Drug resistance in cancer: an overview. Cancers (Basel) 6, 1769-1792.

63. William P, Vincent AM, Katerina AP, Gregory JR, Romel S, Maureen, FZ, Harold V (2005) Acquired resistance of lung adenocarcinomas to gefitinib or erlotinib is associated with a second mutation in the EGFR kinase domain. PLoS Med 2, e73.

64. Gajria D, Chandarlapaty S (2011) HER2-amplified breast cancer: mechanisms of trastuzumab resistance and novel targeted therapies. Expert Rev Anticancer Ther 11, 263-275.

65. Zeller C, Brown R (2010) Therapeutic modulation of epigenetic drivers of drug resistance in ovarian cancer. Ther Adv Med Oncol 2, 319-329.

66. Su HY, Lai HC, Lin YW, Liu CY, Chen CK, Chou YC, Lin WC, Lin SP, et al (2010) Epigenetic silencing of SFRP5 is related to malignant phenotype and chemoresistance of ovarian cancer through Wnt signaling pathway. Int $J$ Cancer 127, 555-567.

67. Verdone L, Agricola E, Caserta M, Di Mauro E (2006) Histone acetylation in gene regulation. Brief Funct Genomic Proteomic 5, 209-221.

68. Hua S, Wu SY (2018) Editorial: Advances and challenges in nanomedicine. Front Pharmacol 9, ID 1397.

69. Danhier F, Feron O, Préat V (2010) To exploit the tumor microenvironment: Passive and active tumor targeting of nanocarriers for anti-cancer drug delivery. $J$ Control Release 148, 135-146.

70. John JV, Uthaman S, Augustine R, Chen H, Park IK, Kim I (2017) pH/redox dual stimuli-responsive sheddable nanodaisies for efficient intracellular tumourtriggered drug delivery. J Mater Chem 5, 5027-5036.

71. Dong Z, Feng L, Zhu W, Sun $X$, Gao M, Zhao, $\mathrm{H}$, Chao Y, Liu Z (2016) $\mathrm{CaCO}_{3}$ nanoparticles as an ultra-sensitive tumor-pH-responsive nanoplatform enabling real-time drug release monitoring and cancer combination therapy. Biomaterials 110, 60-70.

72. Muz B, de la Puente P, Azab F, Azab AK (2015) The role of hypoxia in cancer progression, angiogenesis, metastasis, and resistance to therapy. Hypoxia 1, 83-92.

73. Brown JM, Wilson WR (2004) Exploiting tumour hypoxia in cancer treatment. Nat Rev Cancer 4, 437-447.

74. Yang G, Xu L, Xu J, Zhang R, Song G, Chao Y, Liu $\mathrm{Z}$, Feng L, et al (2018) Smart nanoreactors for $\mathrm{pH}$ responsive tumor homing, mitochondria-targeting, and enhanced photodynamic-immunotherapy of cancer. Nano Lett 18, 2475-2484.

75. Roy A, Li SD (2016) Modifying the tumor microenvironment using nanoparticle therapeutics. Wiley Interdiscip Rev Nanomed Nanobiotechnol 8, 891-908.

76. Franco OE, Shaw AK, Strand DW, Hayward SW (2010) Cancer associated fibroblasts in cancer pathogenesis. Semin Cell Dev Biol 21, 33-39.

77. Ji T, Zhao Y, Ding Y, Wang J, Zhao R, Lang J, Qin H, Liu X, et al (2016) Transformable peptide nanocarriers for expeditious drug release and effective cancer therapy via cancer-associated fibroblast activation. Angew Chem Int Ed Engl 55, 1050-1055.

78. Binnemars-Postma K, Storm G, Prakash J (2017) Nanomedicine strategies to target tumor-associated macrophages. Int J Mol Sci 18, ID 979

79. Huang Z, Zhang Z, Jiang Y, Zhang D, Chen J, Dong L, Zhang J (2012) Targeted delivery of oligonucleotides into tumor-associated macrophages for cancer immunotherapy. J Control Release 158, 286-292. 